\title{
Brain mix-up leaves BSE research in turmoil
}

Declan Butler

In a report that could have plunged the British meat industry back into crisis, parliament was due to receive research results this week confirming that traces of bovine spongiform encephalopathy (BSE) had been found in sheep.

But at the eleventh hour, the Department for Environment, Food and Rural Affairs (DEFRA) declared that the experiments conducted by the Institute for Animal Health (IAH) near Newbury, Berkshire, were suspect.

DEFRA's statement, given on 17 October, revealed the results of tests by the Laboratory of the Government Chemist (LGC) near London. These, the department said, showed that IAH researchers had spent five years and $\mathfrak{2} 217,000$ (US\$308,000) accidentally testing cow brains instead of sheep brains for BSE. The episode was publicly characterized by John Krebs, chairman of the Food Standards Agency, as a "cock-up".

But since DEFRA's statement was issued, it has emerged that the LGC's findings are themselves open to dispute. Moreover, experts say, the IAH's experiment might never have definitively answered the question of whether BSE is present in sheep.

Indeed, following the government statement, one of its own scientific advisers, who requested anonymity, said that Britain's approach to BSE research was "characterized by a lack of external quality control and peer review". The only thing proven by the episode, another adviser said, was that "there has not been and still isn't any proper, large, well-designed study to ascertain whether BSE exists in sheep".

\section{Masked invader}

According to previous experiments done at the IAH (see J. D. Foster, J. Hope \& H. Fraser Vet. Rec. 133, 339-341; 1993), sheep fed infected cattle brain can develop BSE. Until a ban in July 1988, British sheep were fed BSE-contaminated meat and bone-meal (see Nature 395, 6-7; 1998). But scrapie a spongiform encephalopathy similar to BSE, which does not seem to transmit to humans - is endemic in British sheep, and its symptoms are indistinguishable from those of BSE. So it is not known whether BSE has entered the sheep population and is being masked by scrapie.

The experiment at the centre of the controversybegan in 1997 as an examination of a slurry of almost 3,000 brains of scrapieinfected sheep, collected by scientists at Britain's now-defunct Ministry of Agriculture, Fisheries and Food.

The tests used a technique, pioneered by Moira Bruce at the IAH's laboratory in Edinburgh, to discriminate between BSE

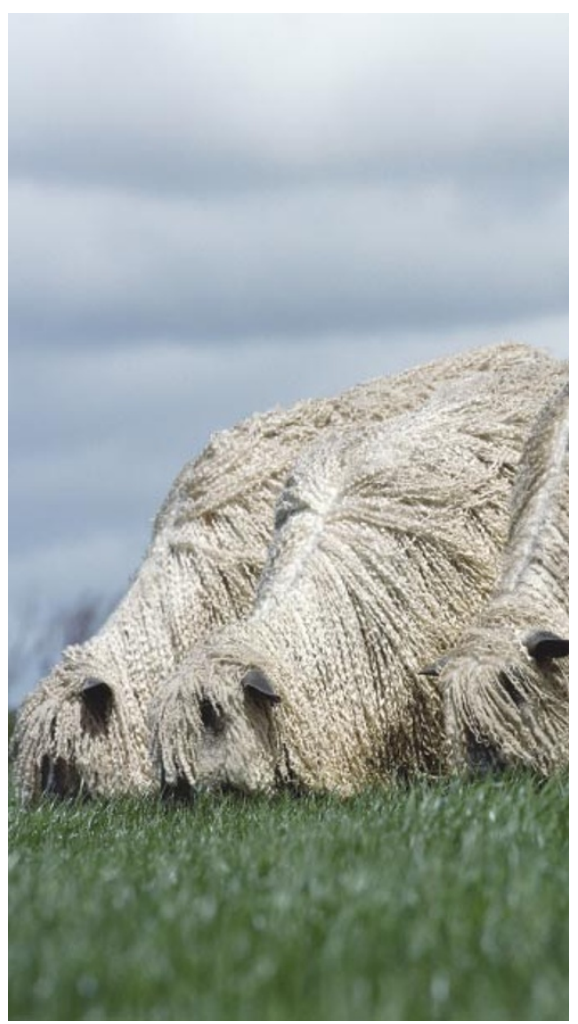

Unknown quantity: despite research, it remains impossible to say whether British sheep have BSE.

and scrapie. In this method, mice are injected with sheep extracts, and the incubation times and brains of mice that succumb to the disease are analysed. But the whole process can take up to two years.

Some researchers were critical of the experiment design from the outset. Because all of the sheep-brain samples were pooled together, they say, there was the possibility of contamination with cow brains held in the same laboratories, as they were excised on the same slabs. The experiment also lacked controls using samples spiked with BSE.

And although the experiment might have established that feed had infected sheep in the early 1990s — something that would surprise few specialists in the field - it could not have answered the key question of whether enough sheep were infected to trigger contagious spread of BSE in the flock. BSE is not contagious in cattle, but some experts worry that in sheep it might transmit in a similar way to scrapie, and spread though the national flock.

The government had established that the preliminary results of the IAH experiment indicated a prevalence of BSE of between $0.1 \%$ and $1 \%$ in sheep - even at $0.1 \%$ this would have had serious implications for public health. On this basis, according to members of the Spongiform Encephalopathy Advisory Committee (SEAC), which advises the UK government on matters related to such 'prion diseases', the government was prepared to announce the findings to parliament, until DEFRA revealed that the sheep-brain samples in the experiment were, in fact, cow brains.

But Chris Bostock, director of the IAH, complains of what he terms the "completely unscientific manner" in which the matter has been handled by DEFRA. Despite requests, he says, the institute has yet to obtain copies of the protocols used by the LGC or of its results. Several members of SEAC also say that they have not had an opportunity to review the data.

\section{Sample questions}

Although DEFRA's announcement has been portrayed as meaning that the IAH results are flawed, Bostock says that there is merely a "discrepancy" between the LGC's assessment and that of his own scientists. He says that the IAH had earlier carried out its own tests to verify the source of its samples, looking for arginine at position 171 on the prion protein linked to scrapie - a signature considered unique to sheep. The results were positive, he says.

Samples were also sent earlier this year to the government's Central Veterinary Laboratory $(\mathrm{CVL})$ in Weybridge, Surrey, he says, which found no evidence of bovine material. But on 19 October, two days after DEFRA announced its findings, the CVL informed Bostock by e-mail that its earlier results could not be relied upon, as a mix-up of samples had occurred.

In addition, Nature has learnt that the samples sent to the LGC frozen in dry ice were delayed and reached the laboratory at room temperature. Whether this affected the outcome of the LGC's tests is uncertain, but one member of SEAC, who had not been informed of this fact, says he remarked on seeing the LGC data that he was surprised that the DNA seemed "highly degraded". Bostock says that frozen duplicates are now "being kept under lock and key", pending the outcome of an internal inquiry into the affair.

Meanwhile, other experiments are under way at the IAH to test 180 individual sheep brains for BSE. But critics say that such a small sample is unlikely to detect BSE at levels of around $0.1 \%$. They argue for diagnostic tests that could test thousands of samples in weeks. From January of next year, the European Union plans to use such techniques to monitor sheep for prion diseases.

Last week's events may yet have regulatory repercussions. On 26 October, the European Union is expected to release new guidelines on public-health controls needed to counter the risk of BSE in sheep. Several advisers to the UK government also argue that existing measures should be reinforced to acknowledge this risk more fully. 